\title{
Analisa Pengaruh Variasi Media Pendingin pada Proses Heat Treatment Metode Hardening- Tempering Material Baja S45C terhadap Sifat Mekanik dan Struktur Mikro
}

\author{
Aldi Wahyu Permana*, Ratna Dewi Anjani, Iwan Nugraha Gusniar \\ Fakultas Teknik, Universitas Singaperbangsa Karawang, \\ Jl. HS. Ronggo Waluyo No.70, Puseurjaya, Telukjambe Timur, Kaupaten.Karawang, JawaBarat 41361 \\ *E-mail: aldi.wahyu15011@student.unsika.ac.id
}

\begin{abstract}
Abstrak
Dalam kehidupan sehari-hari manusia selalu berdampingan dengan peralatan dan teknologi sebagai penunjang kehidupan, banyak peralatan dan teknologi yang dibuat dari bahan logam contohnya seperti poros roda pada sepeda motor. Tentunya logam yang diperlukan harus memiliki karakteristik masing-masing. Contohnya dalam hal kekerasan pada logam. Kekerasan pada logam dapat ditingkatkan dengan beberapa cara. Salah satunya dengan proses hardening. Proses ini merupakan proses perlakuan panas pada logam dengan cara dipanaskan kemudian didinginkan dengan suhu tertentu. Di pasar tradisional banyak limbah air kelapa parut yang tidak dimanfaatkan dan bisa digunakan untuk salah satu media pendingin diproses hardening. Maka dari itu penulis akan memanfaatkan hasil limbah air kelapa parut ini sebagai salah satu media pendingin proses hardening. peneliti meneliti terkait pengaruh variasi media pendingin proses heat treatment terhadap sifat mekanik dan struktur mikro dengan tiga variasi pendingin, air garam, air kelapa, dan air radiator. Temperatur $865^{\circ} \mathrm{C}$ untuk proses hardening dan $465^{\circ} \mathrm{C}$ untuk proses tempering. kegiatan penelitian meliputi uji kekerasan dan struktur mikro. Dari hasil penelitian menunjukan media pendingin air garam proses hardening memiliki nilai kekerasan tertinggi $275,6 \mathrm{Hv}$ sedangkan kekerasan terendah didapatkan pada media pendingin air kelapa yang telah melakukan proses tempering dengan kekerasan 219,3Hv. Hal ini dipengaruhi oleh SOQ (Severity Of Quenching) atau disebut kemampuan media pendingin, untuk air garam SOQ nilainya 5,0 dan untuk air kelapa di bawah 2,055. Sementara itu untuk struktur mikro dapat diketahui media pendinginan air garam proses hardening memiliki struktur yang lebih halus dibandingkan dengan spesimen pendinginan yang lainnya. Sementara pada proses tempering, martensit berubah menjadi ferrite sementite yang lebih halus dengan hasil kekerasan $269,3 \mathrm{Hv}$.
\end{abstract}

Diterima: 03-10-2020; Direvisi: 05-12-2020; Dipublikasi: 28-12-2020

Kata Kunci : Hardening, Media Pendingin, Struktur Mikro, Tempering.

\begin{abstract}
In daily life, human always need every tools and technologies. Many tools and technologies are made by metal. Example shaft on motorcycle. Of course metal which needed, must have their characteristics. For example in their hardness. Metal hardness can improve with many step. One of them is the hardening process. This process is a process of heat treatment of metal by heating and then cooling it to a certain temperature. In traditional markets, a lot of grated coconut water waste is not utilized and can be used as a hardening cooling medium. Therefore, the authors will use the results of this shredded coconut waste as a cooling medium for the hardening process. Researchers the effect of examine variations in the cooling process media of the heat treatment process on the mechanical properties and microstructure with three variations of cooling, salt water, coconut water, and radiator coolant. Temperature $865 C$ for hardening process and $465 C$ for tempering process. research activities including the hardness and micro structure testing. The results show that the hardening process brine cooling medium with the highest hardness value was $275.6 H v$ while the lowest hardness was found in the coconut water cooling medium which had carry out the tempering process with a hardness of 219.3Hv. This is recognized by SOQ (Severity Of Quenching) or the so-called cooling media capability, for SOQ brine the value is 5.0 and for coconut water is below 2.055. Meanwhile, for the microstructure, it can be seen that the hardening process brine cooling medium has a better structure than the other cooling specimens. Meanwhile, in the tempering process, the martensite turned into better cementite ferrite with a hardness of $269.3 \mathrm{Hv}$.
\end{abstract}

Keywords: Hardening, Quenching, Microstructure, Tempering.

\section{Pendahuluan}

Dalam kehidupan sehari-hari manusia selalu berdampingan dengan peralatan dan teknologi sebagai penunjang kehidupan, banyak peralatan dan teknologi yang dibuat dari bahan logam, contohnya seperti poros roda pada sepeda motor yang memerlukan proses heattreatment agar poros tersebut lebih kuat dan tahan lama. Oleh karena itu produksi 
perusahaan yang berhubungan dengan logam setiap harinya meningkat. Tentunya logam yang diperlukan harus memiliki karakteristik masing-masing. Contohnya dalam hal kekerasan pada logam. Kekerasan pada logam dapat ditingkatkan dengan beberapa cara. Salah satunya dengan proses hardening. Proses ini merupakan proses perlakuan panas pada logam dengan cara dipanaskan kemudian didinginkan dengan suhu tertentu.

Proses hardening ini adalah dengan memberikan sifat keras pada logam itu sendiri. Menurut [7] Proses hardening berguna untuk memperbaiki kekerasan dari baja tanpa mengubah komposisi kimia secara keseluruhan. Menurut [2] Kekerasan didefinisikan sebagai ketahanan bahan terhadap penetrasi pada permukaannya.. Beberapa kasus, proses hardening banyak dilakukan pada material baja. Dimana pada material baja, memiliki sifat hardenability [12], dengan adanya sifat ini pada material baja dapat dikeraskan dengan pembentukan martensite. Pembentukan ini didasari pada proses pergeseran atom yang melibatkan penyusutan pada struktur kristal.

Dalam proses hardening ada beberapa faktor yang mempengaruhi hasil kekerasan, antara lain : temperatur, waktu dan laju pendinginan [5]. Laju pendinginan dihasilkan oleh media pendingin yang digunakan dalam suatu proses pendinginan secara cepat yang disebut juga dengan proses quenching. Proses ini menggunakan beberapa media dalam mendinginkan baja dengan suhu tinggi. Pada tahap quenching akan menghasilkan larutan padat lewat jenuh (Super Saturated Solid Solution) yang merupakan fasa tidak stabil pada temperatur biasa atau temperatur ruang [9]. Media dalam proses quenching juga berbeda beda, seperti air, oli bensin dan sebagainya yang dapat menghasilkan kekerasan maksimal dari transformasi struktur austenite pada suhu tinggi menjadi struktur martensit tanpa terjadi pembentukan struktur perlit atau bainit [15]. untuk pendinginan yang cepat biasanya digunakan air garam,soda api yang dimasukkan ke dalam air [1].

Dalam industri rumahan banyak ditemukan industri penjualan kelapa parut, dari kelapa parut tersebut hanya diambil daging kelapanya saja, tetapi airnya sendiri tidak digunakan dan dibuang begitu saja oleh penjualnya. air kelapa ini bisa digunakan untuk salah satu media pendingin di proses hardening. Maka dari itu penulis akan memanfaatkan hasil limbah air kelapa parut ini sebagai media pendingin proses hardening.

Air kelapa memiliki kandungan elektrolit lebih besar dari air putih biasa yang menyebabkan air tersebut sulit membeku atau mendidih [8]. Air Garam dipakai sebagai bahan pendingin disebabkan memiliki sifat mendinginkan yang teratur dan cepat. Larutan garam mampu mengurangi pengaruh buruk proses pemanasan dan pendinginan yang tidak seragam. Pemanasan dan pendinginan yang tidak seragam dapat menyebabkan distorsi/perubahan bentuk dan retak [14]. Penggunaan Air radiator sebagai media pendingin dikarenakan radiator coolant mengandung ethylene glycol dan additive yang berguna menaikkan titik didih dan mencegah terjadinya korosi [3].

Tujuan penelitian ini untuk pemananfaatan limbah air kerlapa yang tidak digunakan dan Mendapatkan paramater nilai kekerasan tertinggi dan terendah dari proses hardening-tempering dengan media pendingin yang berbeda Serta mendapatkan gambar strutur mikro dari proses tersebut.

\section{Material dan Metodologi}

\subsection{Material}

Material yang digunakan adalah baja karbon S45C. Menurut [13] baja S45C adalah baja yang mempunyai kadar karbon sekitar 0,51\%, dan tergolong baja karbon menengah. Dengan ukuran diameter $40 \mathrm{~mm}$ x $20 \mathrm{~mm}$ dan dengan komposisi Karbon (C) 0,44\%, Silikon (Si) 0,25\%, Mangan (Mn) 0,71\%, Fosforus (P) 0,012\%, Tembaga (S) 0,003\%, Kromium (Cr) 0,11\%,Nikel (Ni) 0,02\%,Tembaga (Cu) 0,01\%. Lebih jelas dapat dilihat pada Tabel 1 dibawah ini: 
Tabel 1. Komposisi Material Baja S45C

\begin{tabular}{cccccccccc}
\hline \multirow{2}{*}{$\begin{array}{c}\text { Komposisis } \\
\%\end{array}$} & $\mathrm{C}$ & $\mathrm{Si}$ & $\mathrm{Mn}$ & $\mathrm{P}$ & $\mathrm{S}$ & $\mathrm{Cr}$ & $\mathrm{Ni}$ & $\mathrm{Cu}$ \\
\cline { 2 - 8 } & 0,44 & 0,25 & 0,71 & 0,012 & 0,003 & 0,11 & 0,02 & 0,01 \\
\hline
\end{tabular}

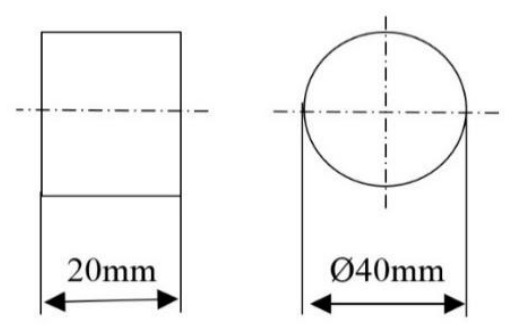

Gambar 1. Gambar teknik material yang digunakan

\subsection{Metodologi}

Material baja S45C dilakukan proses heattreatment metode hardening dengan temperatur 865C dengan penahanan waktu pemanasain (holding time) 96 Menit di dalam tungku pemanas muffle furnace. Kemudian material dilakukan proses quenching dengan media air garam, air kelapa dan air radiator secara cepat dan didinginkan dengan temperatur suhu ruang. Lalu sebagian material di masukan kembali ke dalam tungku pemanas muffle furnace untuk dilakukan proses tempering dengan suhu $465^{\circ} \mathrm{C}$ dengan penahanan waktu pemanasan (holding time) 86 Menit dan didinginkan dengan temperatur suhu ruang. Holding time dilakukan untuk mendapatkan kekerasan maksimum [4].

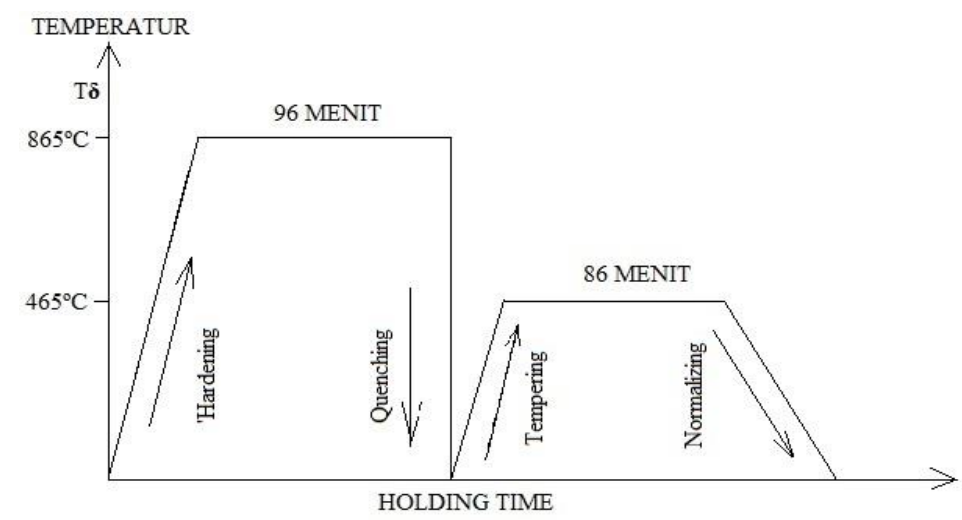

Gambar 2. Diagram pemanasan dan pendinginan proses heattreatment

Setelah melakukan heattreatment kemudian material dilakukan proses pengujian uji kekerasan vickers dengan menggunakan standar ASTM E 92-82 (Reapproved 2003) dengan alat ZWICK NS:61029. uji kekerasan vikers bertujuan menentukan kekerasan suatu material dalam yaitu daya tahan material terhadap indentor intan yang cukup kecil dan mempunyai bentuk geometri berbentuk piramida [11]. Dan pengujian struktur mikro dengan menggunakan standar ASTM E 407-07 dengan alat Microscope BX53M.

\section{Hasil dan Pembahasan}

Pengujian kekeras dan uji struktur mikro dari baja hasil hardening dan tempering dengan media pendinginan air garam, air kelapa, dan air coolant radiator mendapatkan hasil uji sebagai berikut: 
Wahyu Aldi Permana dkk. /Jurnal Rekayasa Mesin

p-ISSN: 1411-6863, e-ISSN: 2540-7678

Vol.15|No.3|199-206|Desember|2020

\subsection{Pengujian Kekerasan}

Pengujian kekerasan menggunakan uji vickers pada spesimen material hardening suhu $865^{\circ} \mathrm{C}$ dan tempering pada suhu $465^{\circ} \mathrm{C}$ dengan media oli, air garam, dan air radiator. Pengujian dilakukan pada tiga titik, penekanan selama 15 detik, beban penekanan pada uji keras sebesar $1471 \mathrm{~N}$, dan hasil nilai yang didapat merupakan HV. Uji keras yang digunakan menggunakan uji keras Hadrnes Vickers dengan menguji baja dari titik yang sudah ditentukan, berikut merupakan hasil dari uji keras vickers. Lebih jelas dapat dilihat pada Tabel 2 dan Tabel 3 di bawah ini:

Tabel 2. Hasil Uji Keras Hardening Baja S45C

\begin{tabular}{cccccc}
\hline \multirow{2}{*}{ NO } & Media Quenching Hardening & \multicolumn{2}{c}{ Uji Kekerasan (Vickers) $10 \mathrm{kgf} / \mathrm{mm}^{2}$} & \multirow{2}{*}{ Rata-rata } \\
\cline { 3 - 4 } & Suhu 865C & Titik 1 & Titik 2 & Titik 3 & \\
\hline 1 & Air Garam & $279 \mathrm{HV}$ & $274 \mathrm{HV}$ & $274 \mathrm{HV}$ & $275,6 \mathrm{HV}$ \\
2 & Air Kelapa & $232 \mathrm{HV}$ & $228 \mathrm{HV}$ & $222 \mathrm{HV}$ & $227,3 \mathrm{HV}$ \\
3 & Air Coolant Radiator & $254 \mathrm{HV}$ & $249 \mathrm{HV}$ & $245 \mathrm{HV}$ & $249,3 \mathrm{HV}$ \\
\hline
\end{tabular}

Pada Tabel 2 merupakan hasil uji kekeasan hardening pada suhu $865^{\circ} \mathrm{C}$ dengan media pendinin air garam, air kelapa, dan air coolant radiator. Pengujian di atas menggunakan uji vickers dengan 3 titik pengujian.

Tabel 3. Hasil Uji Keras Tempering Baja S45C

\begin{tabular}{cccccc}
\hline \multirow{2}{*}{ NO } & Media Quenching Tempering & \multicolumn{2}{c}{ Uji Kekerasan (Vickers) $10 \mathrm{kgf} / \mathrm{mm}^{2}$} & \multirow{2}{*}{ Rata-rata } \\
\cline { 3 - 4 } & Suhu 465C & Titik 1 & Titik 2 & Titik 3 & \\
\hline 1 & Air Garam & $264 \mathrm{HV}$ & $274 \mathrm{HV}$ & $270 \mathrm{HV}$ & $269,3 \mathrm{HV}$ \\
2 & Air Kelapa & $215 \mathrm{HV}$ & $222 \mathrm{HV}$ & $221 \mathrm{HV}$ & $219,3 \mathrm{HV}$ \\
3 & Air Coolant Radiator & $236 \mathrm{HV}$ & $232 \mathrm{HV}$ & $228 \mathrm{HV}$ & $232 \mathrm{HV}$ \\
\hline
\end{tabular}

Pada Tabel 3 merupakan hasil uji kekerasan vicker tempering pada suhu $465^{\circ} \mathrm{C}$ dengan media pendinin air garam, air kelapa, dan air coolant radiator. Pengujian diatas menggunakan uji vickers dengan 3 titik pengujian. Pada tabel di atas akan dikonversikan kedalam grafik untuk menunjukan perbandingan rata-rata dari hasil hardening dan tempering pada material baja S45C. dapat dilihat lebih jelas pada Gambar 3 di bawah ini:

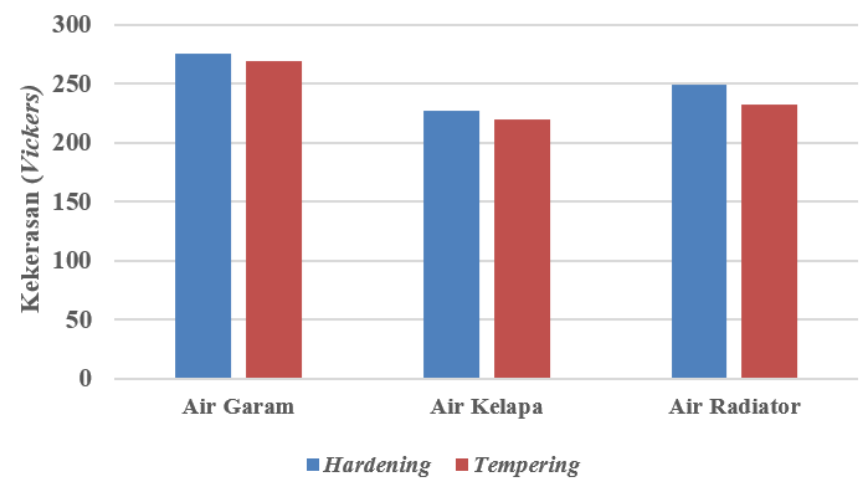

Gambar 3. Grafik perbandingan nilai rata-rata

Pada grafik di atas hasil uji kekerasan pada proses hardening dapat terlihat hasil tertinggi didapatkan oleh baja dengan pendinginan air garam memiliki nilai rata-rata $275,6 \mathrm{HV}$ sedangkan terendah oleh baja dengan media pendinginan air kelapa memiliki nilai rata-rata $227,3 \mathrm{HV}$ hal ini menunnjukan bahwa kemampuan media quenching (Severity Of 
Wahyu Aldi Permana dkk. /Jurnal Rekayasa Mesin p-ISSN: 1411-6863, e-ISSN: 2540-7678

Vol.15|No.3|199-206|Desember|2020

Quenching) air garam lebih kuat diantara air coolant radiator dan air kelapa. Sedangkan hasil uji kekerasan pada proses tempering dapat terlihat hasil tertinggi didapatkan oleh baja dengan pendinginan air garam memiliki nilai rata-rata $269,3 \mathrm{Hv}$ sedangkan terendah oleh baja dengan media pendinginan air kelapa memiliki nilai rata-rata $219,3 \mathrm{Hv}$ hal ini menunjukan bahwa hasil kekerasan tempering memiliki penurunan kekerasan dari hasil hardening. Dan kemampuan media quenching (Severity Of Quenching) pada air garam tetap lebih keras dibandingkan dengan kedua media pendingin lainnya. Lebih jelas dapat dilihat pada Gambar 4.

\begin{tabular}{|l|c|c|c|}
\hline \multirow{2}{*}{ "H" factors - coefficient of severity of quench } \\
\cline { 2 - 4 } & \multicolumn{3}{|c|}{ Cooling medium } \\
\hline None (20-bar $\mathrm{N}_{2}$ ) & $0.25-0.30(0.20)$ & $0.9-1.0$ & 2.0 \\
\hline Mild (20-bar He) & $0.30-0.35(0.35)$ & $1.0-1.1$ & $2.0-2.2$ \\
\hline Moderate & $0.35-0.40$ & $1.2-1.3$ & \\
\hline Good & $0.4-0.5$ & $1.4-1.5$ & \\
\hline $\begin{array}{l}\text { Strong (approx. 150 } \\
\text { fps velocity) }\end{array}$ & $0.5-0.8$ & $1.6-2.0$ & \\
\hline Violent & $0.8-1.1$ & 4.0 & 5.0 \\
\hline
\end{tabular}

Gambar 4. Severity Of Quench [10]

\subsection{Pengujian Struktur Mikro}

Struktur mikro pada hasil penelitian ini diambil dengan menggunakan mikroskop optik. Bentuk penampang mikro dengan pembesaran 200 kali adalah sebagai berikut:

3.2.1. Hasil Pengujian Struktur Mikro Hardening Quenching dapat dilihat lebih jelas pada Gambar 5 (a-c)

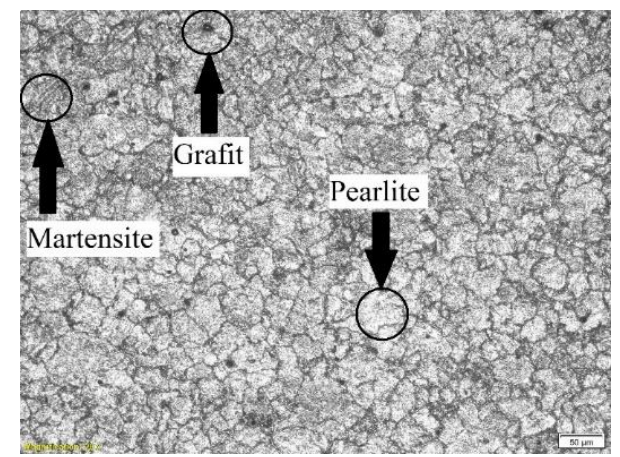

(a)

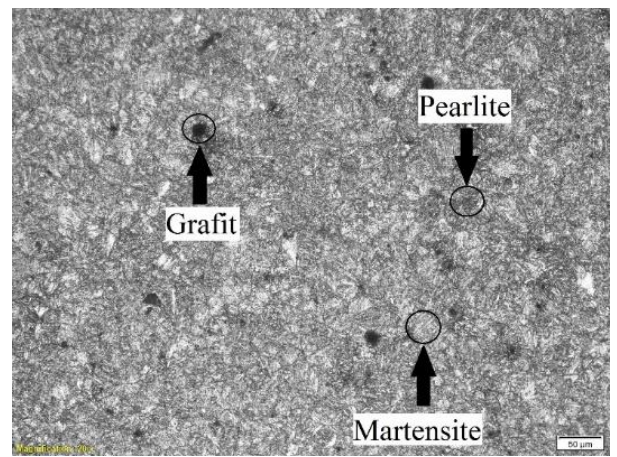

(b)

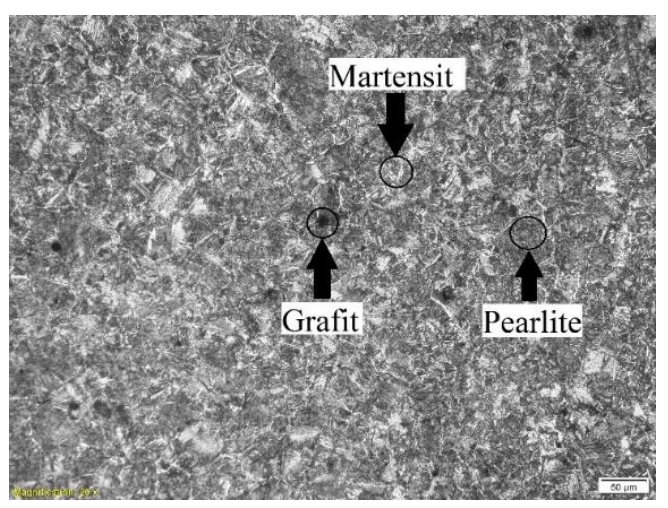

(c)

Gambar 5. (a) Hardening Quenching Air Garam, (b) Hardening Quenching Air Kelapa dan (c) Hardening Quenching Air Radiator 
Wahyu Aldi Permana dkk. /Jurnal Rekayasa Mesin

p-ISSN: 1411-6863, e-ISSN: 2540-7678

Vol.15|No.3|199-206|Desember|2020

Pada Gambar 5 (a) hardening quenching air garam, terlihat memiliki permukaan material dengan batas butir berukuran cukup besar. Gambar 5(b) hardening quenching air kelapa, terdapat batas butir halus banyak, serta terlihat permukaan seperti serat. Gambar 5(c) hardening quenching air radiator, memiliki permukaan dengan batas butir kecil, dapat dilihat struktur yang didapat pada proses hardening yiatu grafit, pearlite dan martensite karna proses quenching / Pendinginan secara cepat mengakibatkan struktur martensite yang bersifat getas.

3.2.2. Hasil Pengujian Struktur Mikro Tempering Quenching dapat dilihat pada Gambar 6 (a-b)

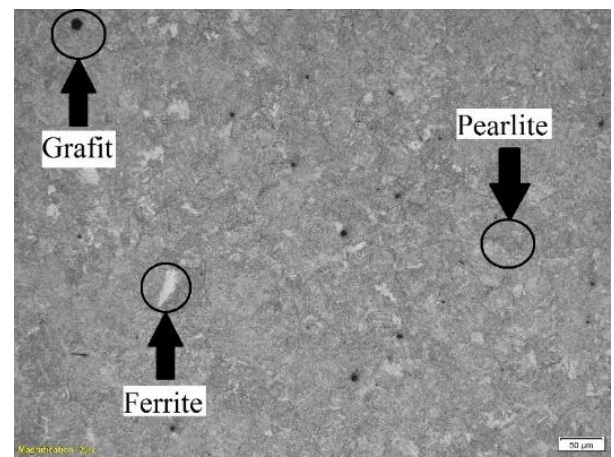

(a)

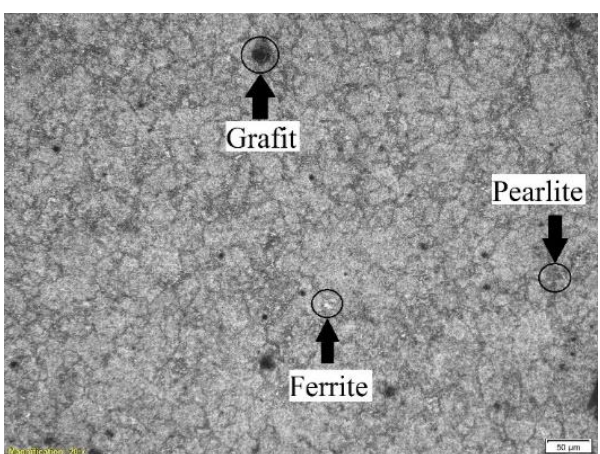

(b)

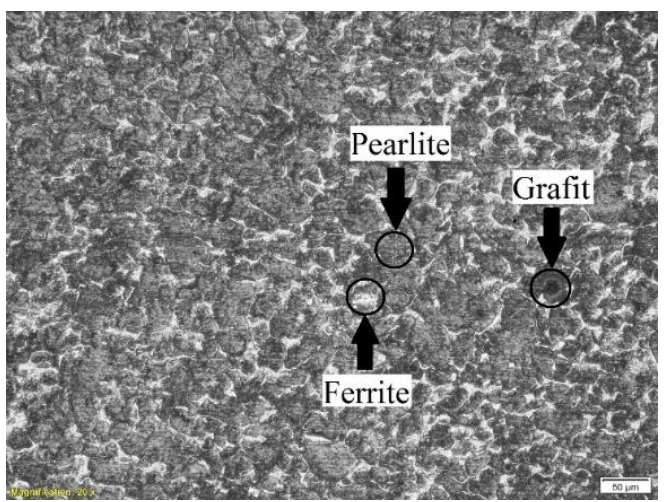

(c)

Gambar 6. (a) Tempering Quenching Air Garam, (b) Tempering Quenching Air Kelapa dan (c) Tempering Quenching Air Radiator

Pada Gambar 6(a) tempering quenching air garam, terlihat permukaan sangat lembut dan halus. Gambar 6(b) tempering quenching air kelapa, terlihat permukaan lebih halus dari hardening air kelapa. Gambar 6(c) tempering quenching air radiator, terlihat banyak batas butir putih yang tebal. Dapat dilihat struktur yang didapat setelah di tempering yaitu struktur pearlite, ferrite, dan grafit. Proses ini mengubah martensite menjadi ferrite, dan grafit tetap ada karena menurut [6] grafit bulat diakbatkan oleh komposisi kimia pada kandungan baja S45C seperti: karbon, silikon, sulfur.

\section{Kesimpulan}

Berdasarkan hasil dari penelitian dan hasil pembahasan tentang variasi media pendingin pada proses heattreatment metode hardening-tempering material baja s45c terhadap sifat mekanik dan struktur mikro telah mendapatkan beberapa kesimpulan. Ditinjau dari hasil uji kekerasan nilai kekerasan tertinggi didapat pada proses hardening pendinginan air garam dengan nilai kekerasan 275,6HV menunjukan bahwa kemampuan media quenching (Severity Of Quenching) air garam lebih kuat diantara air coolant radiator dan air kelapa. Sedangkan nilai kekerasan terendah didapatkan didalam proses tempering hasil hardening pendinginan air kelapa dengan nilai kekerasan 219,3HV hal ini menunjukan bahwa 
Wahyu Aldi Permana dkk. /Jurnal Rekayasa Mesin

p-ISSN: 1411-6863, e-ISSN: 2540-7678

Vol.15|No.3|199-206|Desember|2020

hasil kekerasan tempering memiliki penurunan kekerasan dari hasil hardening. Dan kemampuan media quenching (Severity Of Quenching) pada air garam tetap lebih keras dibandingkan dengan kedua media pendingin lainnya. Karena air garam memiliki nilai SOQ tertinggi dengan nilai SOQ 5,0.

Ditinjau dari hasil uji struktur mikro pengaruh variasi media pendingin yang didapat dari hasil struktur mikro pada proses hardening pendinginan air garam memiliki kekerasan tertinggi serta memiliki struktur martensite, sedikit batas butir dan paling halus diantara spesimen lainnya. Sedangkan hasil struktur mikro pada proses tempering hasil hardening pendinginan air kelapa memiliki kekerasan terendah dan memiliki struktur ferrite dan pearlite yang merata ke seluruh material. Setelah penelitian disimpulkan banyak kelebihan dan kekurangan dari setiap masing-masing media pendingin, media pendingin air garam memiliki kelebihan kekerasan paling tinggi dan mudah ditemukan, kekurangan media air garam memiliki laju pendinginan yang lambat. Media pendingin air kelapa memiliki kelebihan laju pendinginan yang cepat, dalam segi kekurangan air kelapa memiiki kekerasan paling rendah dibandingkan air garam dan air coolant. Media pendingin air coolant radiator memiliki kelebihan laju pendinginan yang cepat, dalam segi kelemahan laju pendinginan air coolant dibawah air kelapa.

\section{Daftar Pustaka}

[1] Amanto, Hari. 1999. Ilmu Bahan. Jakarta: Bumi Angkasa

[2] Sriati Djaprie.,1993., "Metalurgi Mekanik 1", Jakarta, PT. Erlangga.

[3] Yahya Abdul Matien (2016).“ Pengaruh Media Pendingin Terhadap Struktur Mikro, Kekerasan Dan Laju Koroso Pada Hardening Baja Karbon Sedang”. Semarang, Universitas Negi Semarang

[4] Agus Pramono, (2011). "Karakteristik Mekanik Poses Hardening Baja Aisi 1045 Media Quenching Untuk Aplikasi Sprochet Rantai”. Cilegon https://ojs.unud.ac.id/index.php/jem/article/download/2346/1551

[5] Arief Murtiono, (2012). "Pengaruh Quenching dan Tempering Terhadap Kekerasan dan Kekutan Tarik Serta Struktur Mikro Baja Karbon Sedang Untuk Mata Pisau Pemanen Sawit” Jurnal e-Dinamis, Volume II, ISSN 23381035. Sumatra Utara. https://jurnal.usu.ac.id/index.php/edinamis/article/view/2635

[6] Athanasius P. Bayuseno, (2010). "Penambahan Magnesium-Ferrosilikon Pada Proses Pembuatan Besi Cor Grafit Bulat: Evaluasi Terhadap Peningkatan Sifat Mekanik dan Impak". Semarang. https://adoc.tips/penambahanmagnesium-ferrosilikon-pada-proses-pembuatan-besi.html

[7] Bahtiar, M. Iqbal, Supramono. 2014. "Pengaruh Media Pendingin Minyak Pelumas SAE40 Pada Proses Quenching dan Tempering Terhadap Ketangguhan Baja Karbon Rendah”. Jurnal Mekanikal 5(1):455-463 http://simki.unpkediri.ac.id/detail/14.1.03.01.0145.

[8] Hendy Saputra., A. Syarif, Y. Maulana. 2014. Analisa Pengaruh Media Pendingin Terhadap Kekuatan Tarik Baja ST 37 Pasca Pengelasan Menggunakan Las Listrik. Jurnal Ilmiah Teknik Mesin Unlam 3(2):91-98. http://scholar.googleusercontent.com/scholar?q=cache:6ArkKPK8r_kJ:scholar.google.com/\&hl=id\&as_sdt=0,5

[9] Iman Saefuloh, (2018). "Studi Karakterisasi Sifat Mekanik Dan struktur Mikro Material Piston Alumunium-Silikon Alloy" Jurnal Teknik Mesin Untirta Vol. IV hal. 56 - 62. http://jurnal.untirta.ac.id/index.php/jwl/article/view/4010

[10] Jack Titus. 2016. https://www.industrialheating.com/articles/92647-case-hardening-comparing-hpgq-oil-and-salt

[11] Magdalena Feby Kumayasari \& Arif Indro Sultoni, (2017). Jurnal Teknologi Proses dan Inovasi Industri, VOL. 2, NO. 2, http://ejournal.kemenperin.go.id/JTPII/issue/archive 
Wahyu Aldi Permana dkk. /Jurnal Rekayasa Mesin p-ISSN: 1411-6863, e-ISSN: 2540-7678

Vol.15|No.3|199-206|Desember|2020

[12] Rabiatul Adawiyah, (2015). "Pengaruh Beda Media Pendingin Pada Proses Hardening Terhadap Kekerasan Baja Pegas Daun”. Jurnal Poros Teknik Volume 7, No. 1. ISSN 2085-5761 (Print) ISSN 2442-7764 (Online) https://ejurnal.poliban.ac.id/index.php/porosteknik/article/view/195

[13] Taufik Hidayat \& Priyagung Hartono \& Sujatmiko, (2017). “Analisa Pengaruh Suhu Pada Media Pendingin Terhadap Sifat Mekanik Baja S45C Pada Proses http://www.riset.unisma.ac.id/index.php/jts/article/view/706

[14] Yunaidi, 2016 http://e-journal.janabadra.ac.id/index.php/JMST/article/view/YUNAIDI2

[15] Zulfiqar Andhika Suprayogi, Saufik Luthfianto, \& Drajat Samyono. (2017) "Pengaruh Variasi Media Quenching Terhadap Sifat Mekanis Rantai Elevator buah Kelapa Sawit”. P-ISSN : 2303-3142 E-ISSN : 2548-8570 Vol. 6 https://ejournal.undiksha.ac.id/index.php/JST/article/view/9396 